\title{
Attitude and Behaviour For Preventing COVID-19 Disease Infections in Mali: An Analysis Based On COVID-19 Panel Phone Survey
}

\author{
Wilfried GUETS ( $\boldsymbol{\nabla}$ guets@gate.cnrs.fr ) \\ Université Lyon 2: Universite Lumiere Lyon 2 https://orcid.org/0000-0003-0988-5231 \\ Deepak Kumar Behera \\ Manipal Academy of Higher Education
}

\section{Research}

Keywords: Attitude, Behaviour, Coronavirus, COVID-19, Probit model, Prevention, Mali

Posted Date: August 31st, 2021

DOI: https://doi.org/10.21203/rs.3.rs-800944/v1

License: (c) (i) This work is licensed under a Creative Commons Attribution 4.0 International License. Read Full License 


\section{Abstract \\ Background}

COVID-19 outbreak has been declared as an emerging and conflict situation by the World Health Organization (WHO) due to the multiple nature of infection through international spread that poses a serious threat to populations' health and socioeconomic conditions household in general.

\section{Objective}

This study aims to analyse the behaviour adopted by households' heads for preventing COVID-19 infection in Mali.

\section{Methods}

We collected data from the COVID-19 Panel Households survey collected in Mali by the National Statistical Office, Institut National de la Statistique (INSTAT), in collaboration with the World Bank in October 2020. We used a multivariate logistic regression model.

\section{Results}

A total of 1,514 households heads were included. The age between 20 and 90 years old. The poor households represented $27 \%$. Being a household with a low-income reduced the probability of using masks $(p<0.1)$. Being poor increased the probability to agree with vaccination $(p<0.01)$. The health services utilisation increased the probability of wear masks $(p<$ $0.01)$, getting tested $(p<0.01)$, and agree with the vaccine $(p<0.01)$. People with a high occupation volume were more likely to wear protective masks $(p<0.1)$.

\section{Conclusion}

Behaviour and attitude prevention varied according to households characteristics. Local government and policymakers should continue to provide more economic, medical and social assistance to protect the population, which would reduce the spread of the disease, particularly to households living in vulnerable regions of the country most affected by conflict and food insecurity.

\section{Bullet Points (04)}

- Vulnerable households were less likely to wear protective masks but more inclined to agree with the vaccine.

- The health services utilisation was associated with masks wearing, willingness to get tested and agreeing with the vaccine.

- The quality of governance was associated with protective mask-wearing, handwashing, willing to get tested.

- Most households in regions where the poor were located were less likely to agree with the vaccine.

\section{Introduction}

The novel Coronavirus disease (COVID-19) is an infectious disease caused by the severe acute respiratory syndrome of Coronavirus 2 (SARS-CoV-2). COVID-19 has been spread around the globe during the first trimester of 2020. Since 11 March 2020, it has been recognised as a global pandemic by the World Health Organisation (WHO) [1]. This situation was due to its faster transmission characteristics from human to human through common cold and droplets. At the macroeconomic level, 
the COVID-19 affected the worldwide economies and generated more uncertainties on the economic activity evolution. Its social and economic impacts on Africa's Economic Development is not the least of all. A Simulations based on a Computable General Equilibrium (CGE) model indicates that the pandemic would lower revenues from taxes and deteriorate the fiscal deficit [2]. Subsequently, the pandemic's propagation would disproportionately affect the poor and non-poor, particularly in exacerbating food insecurity [3].

Given the uncertainties surrounding the modes of transmission of the pandemic, the WHO has been issued several protective guidelines to prevent the COVID-19 community spread, including wearing masks, sanitise hand or handwashing, maintaining social distancing, and avoiding crowded place [4]. Many countries have tried to follow all guidelines to prevent COVID-19 infections irrespective of the level of risks, such as infection rate, recovery rate, and death rate. Whether the preventive measures have been followed genuinely by the general public or not and whether the general public practice smoothly the COVID-19 preventive measure irrespective of their socio-economic condition is the main challenge across all countries, particularly low-income countries.

Many studies have examined the attitude, knowledge, and behaviour towards practising COVID-19 preventive measures. Some factors influence behavioural differences across populations, like education, employment status, residence area, age variation, health condition, health insurance, household income, trust in media, and government authorities [5-13]. Subsequently, most of them have found that male persons, lower educated people, rural residents, labour class occupation, and poor-income households play a pertinent factor in less practice of preventive measures and knowledge towards COVID19 infection than the counterpart.

Our study has assessed households' behaviour for preventing COVID-19 in a low-income country like Mali on this above backdrop. As on 22 February 2021, the total number of COVID-19 confirmed cases were 8,299, recovered case were 6,298, and total deaths (cumulative total) were 348 [14].[1] The COVID-19 UNICEF-Mali situation reports the highest number of cases and deaths has been recorded in December 2020 since the start of the epidemic (See Figure 1 in Appendix). Currently, 9.4 million doses of vaccine - Astra Zeneca- were ordered to vaccinate around 4.2 million people (20\% of the country's population). Further, the government has taken specific preventive measures to reduce the spread of the COVID-19 pandemic. These measures include establishing sanitary corridors, training to health workers, community radios' engagement for sensitisation on COVID-19, and supply of handwashing kits. Despite those policies, the assessment of individual behaviour towards adopting COVID-19 preventative measures and factors associated with these differences across the population is the central policy questions that should be investigated.

This study examines the household's behaviour on COVID-19 prevention measures. Our analysis is based on behaviour such as mask-wearing, handwashing, willingness to get tested, and agree to be vaccinated using a nationally representative survey in Mali. Earlier literature mostly adopted specific preventive behaviour variables such as mask-wearing, handwashing, avoid crowding, not attending a social function. However, to our knowledge, no study has included the household's willingness to get tested and agree to be vaccinated, which is the most crucial indicator to judge the household's attitude towards the trust of the COVID-19 vaccine. Mostly past studies focus on household's socio-economic characteristics and health conditions to determine their behaviour towards COVID-19. However, we have adopted poverty and governance quality indicators to assess household attitude and behaviour towards adopting COVID-19 prevention, which is probably a unique contribution to this study.

\section{Footnote:}

[1] Update data were found through the COVID-19 Dashboard by the Center for Systems Science and Engineering (CSSE) at Johns Hopkins University (https://systems.jhu.edu/research/public-health/ncov/).

\section{Method And Data}

\subsection{Data sources}

Page 3/13 
We use data from the COVID-19 Panel Households survey collected in Mali by the National Statistical Office, Institut National de la Statistique (INSTAT), in collaboration with the World Bank.[2] This data collection was part of the West African Economic and Monetary (WAEMU) countries to generate high-frequency longitudinal data to assess the impacts of the COVID-19 pandemic in household living conditions. In Mali, data were collected between June (round 1) and October 2020 (round 5) through computer-assisted telephone interviews. We used data from the fifth round, which collected 1,766 households between the 13 and the 27 October 2020. The survey covered several points like to evaluate, within the population, the level of practice of the measures enacted at the national level to prevent the spread of the disease; measuring the impact of the pandemic on access to basic social services; measuring the impact of the pandemic on the employment conditions of the population; understanding the opinion of the population on the practice of governance. The Enquête Hamonisée des conditions de vie des Ménages (EHCVM) survey was the household's main sampling frame. The COVID-19 Panel Households survey was a nationally representative data sets, including both households in the city of Bamako and regions of the country, including residence area (urban/rural) [15].

\subsection{Variables}

The survey questionnaire developed present different variables per section. The section "behaviour" of the survey questionnaire contained variables related to the behaviour of households' head regarding pandemic prevention. Different Information on aspects of protection and prevention were collected. The respondents were asked to answer the following question: "Last week, did you wear protective masks?"(Mask wearing) (1); "Last week, did you wash your hands more than usual?" (handwashing) (2); "If you could get tested for the COVID-19 virus for free, would you be willing to get tested?" (willing to get tested) (3); "If a vaccine approved to prevent the coronavirus were available now at no cost, would you agree to be vaccinated?" (would agree to be vaccinated) (4). We considered the four separated attitudes as dependent variables for prevention behaviour.

Demographic and other household characteristics were collected, such as gender, age; access to health services; perception of the governance; the volume of occupation; region; residence area and poverty. We assumed that these socio-economic and demographics characteristics had influenced the behaviours of households. Further, we examined the possible factors to determine the adoption of COVID-19 preventive measures across geographic regions and poverty status.

\subsection{Methods}

We used descriptive statistics to provide an overview of the study sample. Then, we performed multivariate logistic regression to assess factors associated with the prevention behaviour. We used the following empirical strategy:

$$
\begin{gathered}
\text { Mask }_{i}=\beta_{0}+\beta_{1} \text { Poverty }_{i}+\beta_{2} X_{i}+\varepsilon_{i} \\
\text { WashHand }_{i}=\beta_{0}+\beta_{1} \text { Poverty }_{i}+\beta_{2} X_{i}+\varepsilon_{i} \\
\text { GetTest }_{i}=\beta_{0}+\beta_{1} \text { Povert }_{i}+\beta_{2} X_{i}+\varepsilon_{i} \\
\text { Vaccine }_{i}=\beta_{0}+\beta_{1} \text { Poverty }_{i}+\beta_{2} X_{i}+\varepsilon_{i}
\end{gathered}
$$

Where, Mask $_{i}$ takes the value 1 if the respondent wear masks, and 0 elsewhere; WashHand ${ }_{i}$ takes the value 1 if the respondent said "Yes", and 0 elsewhere; GetTest $t_{i}$ takes the value 1 if the respondent is willing to get tested; and Vaccine ${ }_{i}$ takes the value 1 if the respondent would agree to be vaccinated. The variable Poverty $y_{i}$ is also a dichotomous variable taking the value 1 if the variable was poor[3] and 0 elsewhere. $X_{i}$ contains other explanatory variables. $\beta_{i}$ represents or the parameter to estimate. $\varepsilon_{i}$ stands for the error term. 
All statistical and econometric analysis were performed in STATA SE 64 statistical software 15.1 (StataCorp, LP, College Station, TX, USA).

\section{Footnote:}

[2] https://microdata.worldbank.org/index.php

[3] Poor households were found in the survey's sample drawn from the population of the 2018/19 - Enquête Harmonisée des Conditions de Vie des Ménages (EHCVM) -, which was conducted between October 2018 and July 2019

\section{Results}

\subsection{Descriptive statistics}

Table 1 indicates descriptive statistics of socio-economic, demographic and behavioural characteristics. Our study sample contains 1,514 respondents with complete case (after missing valued removed).

As indicated in Table 1, the mean age was 47 years old, SD \pm 14 , in the range of 20 to 90 years old. Almost $26 \%$ of respondent were poor. The majority of household head ( $90 \%$ ) were male. Almost $77 \%$ of respondent reported the utilisation of health care services. About $40 \%$ agreed with the governance quality and how the crisis was managed. The majority of households (67\%) were living in the urban area. Regarding the geographical location, $24 \%$ were living in the western region, $45 \%$ in the southern region, $23 \%$ in the central region, $6 \%$ in the northern region and $2 \%$ in the Eastern region. Concerning the respondent's behaviour and attitude, $77 \%$ were wearing masks, $91 \%$ were washing hands, $77 \%$ were willing to get tested, and $65 \%$ agreed to be vaccinated.

\section{Table 1: Characteristics of households in Mali}




\begin{tabular}{|c|c|c|}
\hline Variables & $N(1,514)$ & $\%$ \\
\hline \multicolumn{3}{|l|}{ Age (mean \pm SD: $47 \pm 14)$} \\
\hline$[<30]$ & 124 & 8 \\
\hline [30-39] & 385 & 25 \\
\hline [40-49] & 412 & 27 \\
\hline [50-59] & 311 & 21 \\
\hline$[>60]$ & 282 & 19 \\
\hline Poverty & 398 & 26 \\
\hline \multicolumn{3}{|l|}{ Gender } \\
\hline Female & 148 & 10 \\
\hline Male & 1366 & 90 \\
\hline Health services use & 1169 & 77 \\
\hline Volume of occupation & 71 & 5 \\
\hline Governance quality (Good) & 605 & 40 \\
\hline \multicolumn{3}{|l|}{ Residence Area } \\
\hline Rural & 495 & 33 \\
\hline Urban & 1019 & 67 \\
\hline \multicolumn{3}{|l|}{ Region } \\
\hline Western & 368 & 24 \\
\hline Southern & 674 & 45 \\
\hline Central & 355 & 23 \\
\hline Northern & 84 & 6 \\
\hline Eastern & 33 & 2 \\
\hline \multicolumn{3}{|l|}{ Prevention behaviour } \\
\hline Wear protective masks & 1172 & 77 \\
\hline Wash hands & 1377 & 91 \\
\hline Willing to get tested & 1166 & 77 \\
\hline Agree to be vaccinated & 990 & 65 \\
\hline
\end{tabular}

\subsection{Source: Author's estimation}

\subsection{Empirical results}

Table 2 presents the empirical results of factors associated with the household head's behaviour to prevent COVID-19 infections. The poor households were less likely to wear protective masks $(p<0.1)$. However, being poor increased the probability to agree with vaccination $(p<0.01)$. The health services utilisation increased the probability of wear masks $(p<$ $0.01)$, willing to get tested $(p<0.01)$, and agree with the vaccine $(p<0.01)$. People with a high occupation volume were more 
likely to wear protective masks $(p<0.1)$. Good governance quality was associated with household prevention behaviour. These results are essentially significant for wearing protective mark $(p<0.01)$, handwashing $(p<0.05)$, willing to get tested ( $p$ $<0.1)$. Households in the urban area of the country were more likely to wear protective masks $(p<0.05)$ and get tested $(p<$ $0.1)$. In regions, the quasi majority of households were less likely to have preventive behaviours, particularly regarding masks' utilisation, handwashing, and willingness to get tested. Table 2 also indicated the interaction between variable poverty and the region. The empirical model's result indicated that poor households in the quasi-majority of the regions were less likely to accept vaccination $(p<0.01)$.

Table 2: Factors influencing the behaviour of households heads to prevent COVID-19 disease infection 


\begin{tabular}{|c|c|c|c|c|c|c|c|c|}
\hline & (1) & (2) & (3) & (4) & (5) & (6) & (7) & (8) \\
\hline & $\begin{array}{l}\text { Wear } \\
\text { protective } \\
\text { masks }\end{array}$ & $\begin{array}{l}\text { Wash } \\
\text { hands }\end{array}$ & $\begin{array}{l}\text { Willing } \\
\text { to get } \\
\text { tested }\end{array}$ & $\begin{array}{l}\text { Agree to } \\
\text { be } \\
\text { vaccinated }\end{array}$ & $\begin{array}{l}\text { Wear } \\
\text { protective } \\
\text { masks }\end{array}$ & $\begin{array}{l}\text { Wash } \\
\text { hands }\end{array}$ & $\begin{array}{l}\text { Willing } \\
\text { to get } \\
\text { tested }\end{array}$ & $\begin{array}{l}\text { Agree to } \\
\text { be } \\
\text { vaccinated }\end{array}$ \\
\hline \multirow[t]{2}{*}{ Poverty } & -0.210 * & -0.037 & -0.029 & 0.107 & -0.125 & -0.146 & 0.118 & $3.571^{\star \star \star}$ \\
\hline & $(0.086)$ & $(0.110)$ & $(0.087)$ & $(0.082)$ & $(0.135)$ & $(0.129)$ & $(0.666)$ & (0.399) \\
\hline \multirow[t]{2}{*}{ Male } & 0.127 & 0.246 & -0.022 & -0.093 & 0.125 & 0.244 & -0.021 & -0.093 \\
\hline & $(0.128)$ & $(0.147)$ & $(0.125)$ & $(0.116)$ & $(0.127)$ & $(0.146)$ & $(0.125)$ & $(0.117)$ \\
\hline \multirow{2}{*}{$\begin{array}{l}\text { Health services } \\
\text { use }\end{array}$} & $0.433^{\star \star \star}$ & 0.035 & $0.322^{\star \star \star}$ & $0.388^{* * *}$ & $0.431^{\star \star \star}$ & 0.036 & $0.325^{\star \star \star}$ & $0.391^{\star \star \star}$ \\
\hline & $(0.085)$ & $(0.105)$ & $(0.083)$ & $(0.079)$ & $(0.085)$ & $(0.105)$ & $(0.083)$ & $(0.079)$ \\
\hline \multirow{2}{*}{$\begin{array}{l}\text { Volume of } \\
\text { occupation }\end{array}$} & $0.678^{\star}$ & 0.519 & 0.338 & 0.342 & $0.681^{\star}$ & 0.521 & 0.331 & 0.338 \\
\hline & $(0.271)$ & $(0.327)$ & $(0.201)$ & $(0.186)$ & $(0.272)$ & $(0.328)$ & $(0.201)$ & (0.189) \\
\hline \multirow{2}{*}{$\begin{array}{l}\text { Governance } \\
\text { quality }\end{array}$} & $0.255^{\star \star}$ & $0.321^{* *}$ & $0.157^{\star}$ & -0.083 & 0.258 ** & 0.320 ** & $0.162^{\star}$ & -0.079 \\
\hline & $(0.079)$ & $(0.098)$ & $(0.076)$ & $(0.070)$ & $(0.079)$ & $(0.098)$ & $(0.076)$ & $(0.070)$ \\
\hline \multirow[t]{2}{*}{ Urban } & $0.230 * *$ & -0.053 & $0.216^{*}$ & 0.098 & $0.227 * *$ & -0.054 & $0.214^{*}$ & 0.095 \\
\hline & $(0.087)$ & (0.108) & $(0.086)$ & $(0.081)$ & $(0.088)$ & $(0.108)$ & $(0.086)$ & $(0.082)$ \\
\hline \multirow[t]{2}{*}{ Age } & 0.004 & 0.007 & 0.001 & 0.004 & 0.004 & 0.007 & 0.001 & 0.005 \\
\hline & $(0.003)$ & $(0.004)$ & $(0.003)$ & $(0.003)$ & $(0.003)$ & $(0.004)$ & $(0.003)$ & $(0.003)$ \\
\hline \multicolumn{9}{|l|}{ Region } \\
\hline \multirow[t]{2}{*}{ Western } & $-4.698 * * *$ & $-3.775^{\star \star \star}$ & -0.563 & $-1.196^{\star \star \star}$ & $-4.619 * \star \star$ & $-3.828 * * *$ & -0.473 & $-0.947 *$ \\
\hline & $(0.100)$ & $(0.126)$ & $(0.316)$ & $(0.357)$ & $(0.123)$ & $(0.143)$ & $(0.397)$ & $(0.397)$ \\
\hline \multirow[t]{2}{*}{ Southern } & $-4.302^{\star \star \star}$ & $-3.805^{\star \star \star}$ & -0.417 & $-1.023^{\star \star}$ & $-4.281^{\star \star \star}$ & $-3.837 * \star *$ & -0.392 & $-0.835^{\star}$ \\
\hline & $(0.093)$ & $(0.102)$ & $(0.314)$ & $(0.355)$ & $(0.115)$ & $(0.124)$ & $(0.394)$ & $(0.394)$ \\
\hline \multirow[t]{2}{*}{ Central } & $-4.700 * * *$ & $-3.946 * * *$ & -0.397 & $-0.921^{* *}$ & $-4.681^{\star \star \star}$ & $-3.970 * \star *$ & -0.302 & -0.663 \\
\hline & $(0.099)$ & $(0.116)$ & $(0.316)$ & $(0.357)$ & $(0.132)$ & $(0.146)$ & $(0.401)$ & $(0.400)$ \\
\hline \multirow[t]{2}{*}{ Northern } & 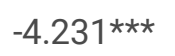 & $-3.534 * * *$ & 0.246 & -0.241 & $-4.186^{\star \star \star}$ & $-3.486 * * *$ & 0.181 & -0.131 \\
\hline & $(0.184)$ & $(0.231)$ & $(0.364)$ & $(0.394)$ & $(0.229)$ & $(0.288)$ & $(0.445)$ & $(0.438)$ \\
\hline \multirow[t]{2}{*}{ Poverty*Western } & & & & & -0.259 & 0.211 & -0.311 & $-3.635^{\star \star \star}$ \\
\hline & & & & & $(0.212)$ & $(0.265)$ & $(0.684)$ & $(0.429)$ \\
\hline \multirow[t]{2}{*}{ Poverty*Southern } & & & & & -0.005 & 0.106 & -0.011 & $-3.337 * \star \star$ \\
\hline & & & & & $(0.190)$ & $(0.209)$ & $(0.679)$ & $(0.417)$ \\
\hline \multirow[t]{2}{*}{ Poverty*Central } & & & & & -0.038 & 0.086 & -0.251 & $-3.584 * \star \star$ \\
\hline & & & & & $(0.193)$ & $(0.219)$ & $(0.680)$ & $(0.423)$ \\
\hline Poverty*Northern & & & & & -0.100 & -0.139 & 0.361 & $-2.932^{\star \star \star}$ \\
\hline
\end{tabular}




\section{$(0.381)$}

$(0.471)$

(0.846)

\begin{tabular}{lllllllll} 
Constant & $4.430^{\star \star \star}$ & $4.505^{\star \star \star}$ & 0.677 & $0.898^{\star}$ & $4.391^{\star \star \star}$ & $4.540^{\star \star \star}$ & 0.613 & 0.675 \\
\hline $\begin{array}{l}\text { No. of } \\
\text { Observations }\end{array}$ & $(0.208)$ & $(0.259)$ & $(0.361)$ & $(0.390)$ & $(0.210)$ & $(0.255)$ & $(0.422)$ & $(0.423)$ \\
\hline
\end{tabular}

Observations

Note: Standard errors in parentheses: ${ }^{*} p<0.05, * * p<0.01, * * * 0.001$

Source: Author's estimation

\section{Discussion}

COVID-19 outbreak has been declared as an emerging and conflict situation by the International Health Emergency Committee headed by the Director-General of World Health Organization due to the multiple nature of infection through international spread that poses a serious threat to populations' health well as socio-economic conditions of household in general. Although few countries have tried the vaccine for the COVID-19 pandemic, it still requires more time for usability and acceptability by the people. So, at this juncture, the prevention of COVID-19 through protective measures is the only sustainable path to control the spread of infection. Therefore, investigating people's behaviour and attitude on the COVID-19 prevention guidelines is of utmost priority in low- and middle-income countries. Thus, our study aimed to examine the factors associated with households behaviour to prevent COVID-19 infection in Mali using a household survey. Our paper assessed pertinent factors influencing households' preventive behaviours: wear protective masks, wash hands, be willing to get tested, and agree to be vaccinated. This assessment would derive the level of hygiene practices, willingness for antigen test, and acceptability on COVID-19 vaccine among households in a low-income country.

Our findings show that most study participants were practising hygiene, such as $77 \%$ of respondents wear protective masks, and $91 \%$ of respondents wash hands frequently. Similarly, around $77 \%$ of study participants were willing to get tested, and only $65 \%$ of respondents were agreed to be vaccinated. Our findings indicated that hygiene practices were acceptable as per the existing literature in low-and middle-income countries. In contrast, hygiene practices are close to $90 \%$ in developed countries or countries more prone to the COVID-19 diseases $[5,7-9,13,16-18]$. None of the past studies examined the level of willingness and acceptability about COVID antigen test and to get vaccinated, respectively. It will be challenging to portray the past literature; however, we can say that Mali's low socio-economic status and low-level income might have factors for the low level of willingness to get tested and agreement to vaccinated.

We found exciting insights by examining the factors influencing the household's head behaviour towards COVID-19 disease prevention using a multivariate logistic regression model. Our results indicated a negative and statistically significant relationship between poverty and wearing a protective mask, as expected from the past literature. A lower usage mask was also noticed across geographical regions in Mali. Some research argues that the COVID-19 pandemic has severe implications for household income loss and food insecurity that exacerbate poverty in low- and middle-income countries, like Kenya and Uganda [19,20] and Mali [3]. Few studies argue that poverty-driven households are usually employed in an unorganised sector in which there was no option for work from home, and there are bound to move to the workplace [21, 22]. So, there could be an apparent reason not to practice wearing masks in the country. On the contrary, the acceptability of the COVID-19 vaccine and agreement to be vaccinated is more common among vulnerable households. It reflects that poor-income households have more trust in the government's COVID-19 strategy because the poor have no other healthcare options due to financial constraints.

Good governance plays a vital role in providing preventive measures and policy direction to reduce Mali's infection rate. Therefore, we have found a positive and statistically significant association between governance quality and people's behaviour on COVID-19 protection. Our results are similar to past studies for low-income countries. Dutta and Fischer (2021) indicated that empowerment of local democratic government and incorporating grass-roots program implementers built a 
bridge between policymakers and population to respect protective measures related to the COVID-19 disease [23]. Nevertheless, in high-income countries like the U.S.A. and U.K, the governance mechanism is not reflected in reached local government level. That might be why it took a longer-time to flatten the COVID-19 infection curve [24].

We found a difference in the COVID-19 protection behaviour between rural and urban residence area. As expected, our result is similar to other studies that urban people are more actively practices COVID-19 preventive measures [5, 8, 16]. However, our study did not found any effects of gender and age on the practice of COVID-19 protection. This finding seems contrary to the earlier literature, which found that the lower education level, male and middle-aged persons, does not adequately use all COVID-19 protection compared to the well-educated, older, and female [10-12, 18, 25]. Further, irrespective of residence, income status of households, governance quality, health services use, there is a disagreement to be vaccinated among households. In this context, few studies argued that people are looking forward to getting the vaccine, but they do not know how to access those facilities [5, 6].

Overall, our study finds that irrespective of households' socio-demographic conditions, there is a significant level of acceptance among Mali people regarding hygiene practices and willingness to get the COVID-19 test due to good governance utilisation of healthcare services. On the contrary regional inequality in poverty plays a determinant role in the behaviour of the household's head to prevent COVID-disease infection. However, we found geographical heterogeneity in adopting COVID19 preventive behaviour, which is an important finding in our study. In this context, we can infer that the COVID-19 management strategy has not reached the grass-roots level. It could show a better result if the policymakers considered potential geographical barriers to access COVID-19 health care services.

\section{Conclusion}

This is the first study to examine the factors that influence the household's behaviour on various COVID-19 preventive measures such as wearing masks, handwashing, willingness to get tested, and agree to be vaccinated in Mali using a nationally representative household survey. Our findings indicate that poverty-driven households are less likely to practice wearing mask across geographical regions in Mali. We found that three pertinent factors positively influence the attitude and behaviour of the household's head, such as urban resident, good governance, and health services use. Nevertheless, we did not find any significant effect of gender and age on determining the household's behaviour. One impressive result indicated that irrespective of socio-economic status, there is less agreement among household to get vaccinated except poor households. This could be trusted by low-income households and regions of the country upon local government and its COVID-19 policy. Our study concludes that behaviour and attitude prevention varied across both geographic regions and socio-economic status in Mali. Few policy suggestions could change the behaviour and attitude of the people toward the practice of COVID-19 protection, such as - first, maintain trust among political institutions and follow the public authorities' guidelines; second, facilitate equity in health care access to households living in vulnerable regions of the country most affected by conflict and food insecurity.

\section{Declarations}

\section{Ethics approval and consent to participate}

Not applicable

\section{Consent for publication}

Not applicable

\section{Data availability}

The data are publicly available on the World Bank Site at https://microdata.worldbank.org/index.php/catalog/3725/studydescription 


\section{Conflict of interest}

The authors have no conflict of interest to declare.

\section{Funding}

The authors declare no funding.

\section{Acknowledgements}

The authors thank the Word Bank Group for the COVID-19 Panel Phone Survey of Households 2020 program and the support and free access to the data. https://microdata.worldbank.org/index.php/catalog/hfps

\section{Authors' contributions}

WG conceptualised the idea and were responsible for the study design. WG conducted the data analysis. DKB and WG were responsible for drafting the manuscript. DKB and WG provided comments on the successive manuscript version. All authors have read and approved the final manuscript.

\section{References}

1. Cucinotta D, Vanelli M. WHO declares COVID-19 a pandemic. Acta Biomed. 2020;91:157-60. https://doi.org/10.23750/abm.v91i1.9397.

2. Djiofack CZ, Dudu H, Zeufack AG. Assessing COVID-19's economic impact in sub-Saharan Africa: Insights from a CGE model. COVID-19 Dev Econ 2020:53.

3. Adjognon GS, Bloem JR, Sanoh A. The Coronavirus Pandemic and Food Security: Evidence from West Africa 2020.

4. World Health Organization. COVID-19 weekly epidemiological update, 16 February 2021. 2021.

5. Abdelhafiz AS, Mohammed Z, Ibrahim ME, Ziady HH, Alorabi M, Ayyad M, et al. Knowledge, Perceptions, and Attitude of Egyptians Towards the Novel Coronavirus Disease (COVID-19). J Community Health. 2020;45:881-90. https://doi.org/10.1007/s10900-020-00827-7.

6. Lee M, You M. Psychological and Behavioral Responses in South Korea During the Early Stages of Coronavirus Disease 2019 (COVID-19). Int J Environ Res Public Health. 2020;17:2977. https://doi.org/10.3390/ijerph17092977.

7. Lau LL, Hung N, Go DJ, Ferma J, Choi M, Dodd W, et al. Knowledge, attitudes and practices of COVID-19 among incomepoor households in the Philippines: A cross-sectional study. J Glob Health 2020;10.

https://doi.org/10.7189/JOGH.10.011007.

8. Ferdous MZ, Islam MS, Sikder MT, Mosaddek ASM, Zegarra-Valdivia JA, Gozal D. Knowledge, attitude, and practice regarding COVID-19 outbreak in Bangladesh: An onlinebased cross-sectional study. PLoS One. 2020;15:e0239254. https://doi.org/10.1371/journal.pone.0239254.

9. Kusuma D, Pradeepa R, Khawaja KI, Hasan M, Siddiqui S, Mahmood S, et al. Low uptake of COVID-19 prevention behaviours and high socioeconomic impact of lockdown measures in South Asia: evidence from a large-scale multicountry surveillance programme. SSM - Popul Heal. 2021;13:100751. https://doi.org/10.1016/j.ssmph.2021.100751.

10. Islam JY, Vidot DC, Camacho-Rivera M. Determinants of COVID-19 preventive behaviours among adults with chronic diseases in the USA: an analysis of the nationally representative COVID-19 impact survey. BMJ Open. 2021;11:e044600. https://doi.org/10.1136/bmjopen-2020-044600.

11. Gao H, Hu R, Yin L, Yuan X, Tang H, Luo L, et al. Knowledge, attitudes and practices of the Chinese public with respect to coronavirus disease (COVID-19): an online cross-sectional survey. BMC Public Health. 2020;20:1-8.

https://doi.org/10.1186/s12889-020-09961-2. 
12. Honarvar B, Lankarani KB, Kharmandar A, Shaygani F, Zahedroozgar M, Rahmanian Haghighi MR, et al. Knowledge, attitudes, risk perceptions, and practices of adults toward COVID-19: a population and field-based study from Iran. Int J Public Health. 2020;65:731-9. https://doi.org/10.1007/s00038-020-01406-2.

13. Zhao E, Wu Q, Crimmins EM, Ailshire JA. Media trust and infection mitigating behaviours during the COVID-19 pandemic in the USA. BMJ Glob Heal. 2020;5:3323. https://doi.org/10.1136/bmjgh-2020-003323.

14. WHO. WHO Coronavirus Disease (COVID-19). Dashboard 2021. https://covid19.who.int/table (accessed February 23, 2021).

15. World Bank. Mali- COVID-19 High Frequency Phone Survey of Households. 2020.

16. ul Haq S, Shahbaz P, Boz I. Knowledge, behavior and precautionary measures related to COVID-19 pandemic among the general public of Punjab province, Pakistan. J Infect Dev Ctries. 2020;14:823-35. https://doi.org/10.3855/jidc.12851.

17. Fisher KA, Barile JP, Guerin RJ, Vanden KL, Jeffers A, Lin; et al. Morbidity and Mortality Weekly Report Factors Associated with Cloth Face Covering Use Among Adults During the COVID-19 Pandemic-United States, April and May 2020. vol. 68. 2020.

18. Pasion R, Paiva TO, Fernandes C, Barbosa F. The AGE Effect on Protective Behaviors During the COVID-19 Outbreak: Sociodemographic, Perceptions and Psychological Accounts. Front Psychol. 2020;11:2785.

https://doi.org/10.3389/fpsyg.2020.561785.

19. Kansiime MK, Tambo JA, Mugambi I, Bundi M, Kara A, Owuor C. COVID-19 implications on household income and food security in Kenya and Uganda: Findings from a rapid assessment. World Dev. 2021;137:105199.

https://doi.org/10.1016/j.worlddev.2020.105199.

20. Torero M. Without food, there can be no exit from the pandemic 2020.

21. Borjas G, Cassidy H. The Adverse Effect of the COVID-19 Labor Market Shock on Immigrant Employment. Cambridge, MA: 2020. https://doi.org/10.3386/w27243.

22. Buheji M, da Costa Cunha K, Beka G, Mavric B, De Souza YL, da Costa Silva SS, et al. The extent of covid-19 pandemic socio-economic impact on global poverty. a global integrative multidisciplinary review. Am J Econ. 2020;10:213-24.

23. Dutta A, Fischer HW. The local governance of COVID-19: Disease prevention and social security in rural India. World Dev. 2021;138:105234. https://doi.org/10.1016/j.worlddev.2020.105234.

24. Wenham C. What went wrong in the global governance of covid-19? BMJ 2021;372. https://doi.org/10.1136/bmj.n303.

25. Al-Hanawi MK, Angawi K, Alshareef N, Qattan AMN, Helmy HZ, Abudawood Y, et al. Knowledge, Attitude and Practice Toward COVID-19 Among the Public in the Kingdom of Saudi Arabia: A Cross-Sectional Study. Front Public Heal. 2020;8:217. https://doi.org/10.3389/fpubh.2020.00217.

\section{Figures}




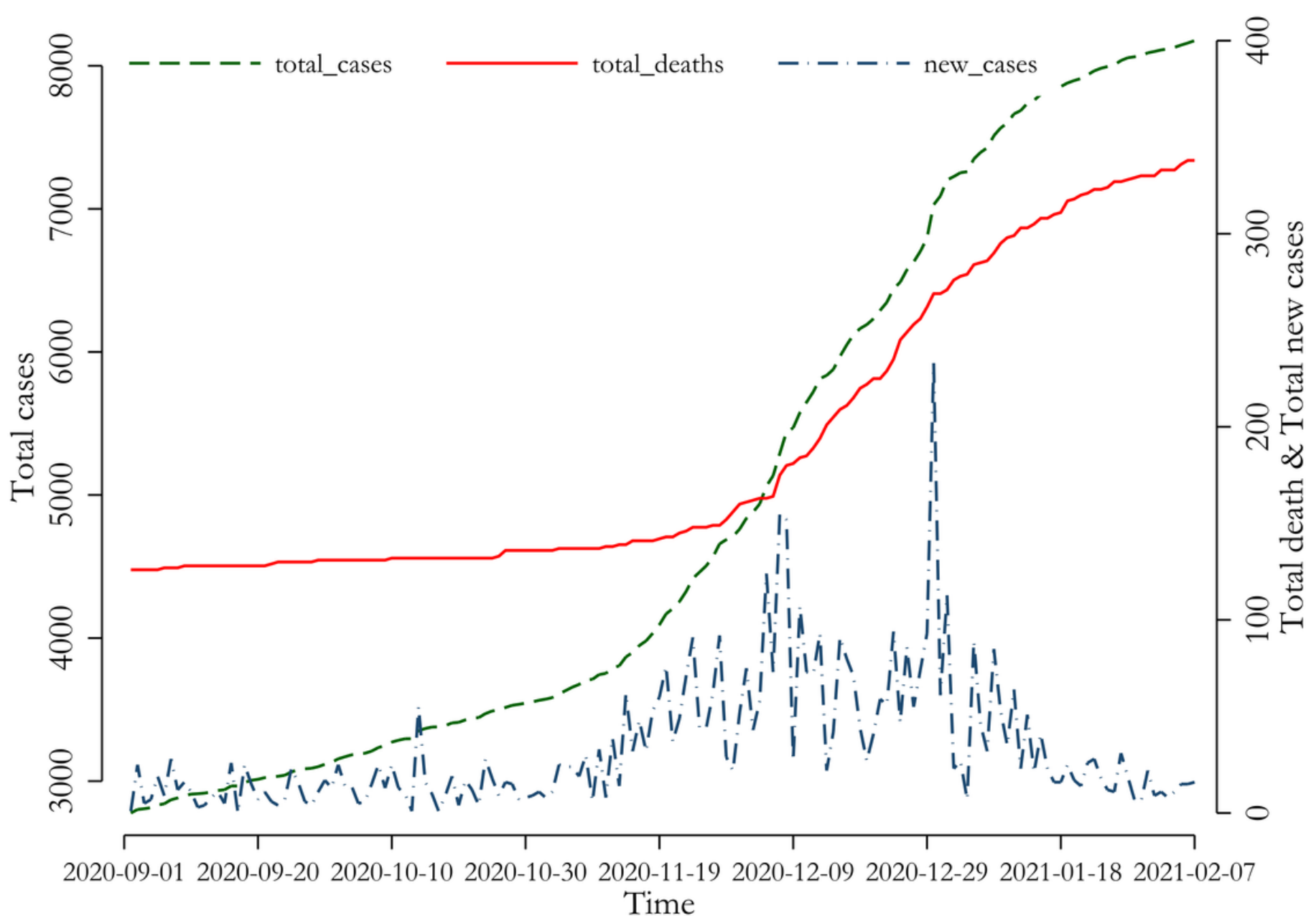

Sources: Authors based on COVID-19 data in Mali - https://ourworldindata.org/coronavirus

Figure 1

Trend of COVID-19 evolution in Mali between September and February 2021 